Jing Wang: The Other Digital China: Nonconfrontational Activism on the Social Web (Cambridge, Massachusetts: Harvard University Press, 2019). [Book review]

Chen, Julie Yu-Wen

2020-09-02

Chen , J Y-W 2020 , ' Jing Wang: The Other Digital China: Nonconfrontational Activism on the Social Web (Cambridge, Massachusetts: Harvard University Press, 2019). [Book review] ' , European Political Science, vol. 19 , no. 3 , pp. 502-503 . https://doi.org/10.1057/s41304-020-00241-6

http://hdl.handle.net/10138/320400

https://doi.org/10.1057/s41304-020-00241-6

acceptedVersion

Downloaded from Helda, University of Helsinki institutional repository.

This is an electronic reprint of the original article.

This reprint may differ from the original in pagination and typographic detail.

Please cite the original version. 


\title{
MIT action researcher in China
}

\author{
Yu-Wen Chen \\ University of Helsinki, Finland and Palacky University, Czech Republic \\ julie.chen@helsinki.fi
}

\section{Book reviewed:}

The Other Digital China: Nonconfrontational Activism on the Social Web

Jing Wang (Cambridge, Massachusetts: Harvard University Press, 2019), 320 pp. ISBN: 9780674980921

The Other Digital China: Nonconfrontational Activism on the Social Web is an unconventional book on the usage of digital tools to advance so-called nonconfrontational social activism in China. The reason it is unconventional is that its author, Jing Wang, Professor of Chinese Media and Cultural Studies at the Massachusetts Institute of Technology (MIT), has unabashedly written a supposedly academic book on the basis of her civic engagements in China. As Wang admitted in her book, some scholarly colleagues have questioned the academic nature and value of her work. However, Wang has firmly believed in her project and advocated the need of her type of participatory action research (PAR) in the study of China. The ultimate aim of her academic-activist project is to transform and improve Chinese society in which she has deep ancestral roots and for which she apparently has a personal compassion. Her call to empower Chinese non-governmental organisations (NGOs) with rights digital tools to gather resources and advance their philanthropic ambition is unflinchingly personal and strong. Her method shows that it is possible to work nonconfrontationally vis-à-vis the authoritarian Chinese state, gathering the momentum of likeminded activists and ordinary people to transform Chinese society for the better.

Wang is not the first scholar to have observed the massive potential of using nonconfrontational tactics to gather social momentum for reform and change in China. Many scholars have noted this potential and attempted to develop different terminologies and theories or borrow those from elsewhere (i.e. where there is also an authoritarian state and social activism) to analyse the case of China. However, Wang is one of the rare scholars based in the west to have actually led social activism in China and decided to make her activism part of her academic project. Because the nature of nonconfrontational tactics involves discretion, scholars frequently cannot pinpoint how these undercurrents change and expand their influences, despite having knowledge of their existence. Wang's position as an insider has provided her advantages to gain perspectives and insights that other social or political scientists may not gain on this topic.

In terms of structure, the book begins with a review of the concept of society in the Chinese context and discusses the crucial role of the state in legitimising the social space. The often westernbred bias in treating state and society as two separate entities contesting each other is not relevant here, and Wang clarifies that she wishes to move away from such a binary vision. The subsequent chapters offer several examples of how hardware techies and IT corporations work with NGOs to produce social benefits. Only in the penultimate chapter does Wang explain her usage of PAR as a method for her research. It is fascinating that she shares how Chinese and Taiwanese researchers have exchanged views on the utility of the PAR method and created an epistemic community of PAR for their local conditions. Even the socio-political conditions of Taiwan and China differ, action researchers in the People's Republic of China seem extremely open to engaging in dialogues with Taiwan's action researchers in this regard. The boldness and creativeness of these Chinese and Taiwanese action researchers is inspiring and encouraging.

In addition, because of Wang's multi-positionality in her social and academic project, this book is an interesting read compared to other similar works in the field. I appreciate her honesty and openness in sharing her emotions, convictions, doubts, and the challenges and triumphs she has faced 
in her dual role as a scholar and activist. I welcome her witty anecdotal remarks on how officials who were originally assigned to monitor her eventually joined her cause. Her approach brings readers closer to the distant draconian state of China. We are able to see Chinese officials who can be persuaded on the value of civic engagement to generate social benefits. We also see how tactful deployment of humour in digitally-mediated civic campaigns can soften the hearts of officials and gently promote actual social change in China.

The Other Digital China is a unique and necessary work. I wish that it will remain unchanged. However, I know political scientists will sometimes not be satisfied with the book's descriptive narration of the situations in China. This criticism can be applied to many similar works in this field, such as the academic writings on China's fragmented authoritarianism and its various versions. These works lack formal theoretical modelling for political scientists to draw clear causal relationships between variables and further make predictions. For scholars of humanity-related disciplines, such as Area Studies and Cultural Studies, however, The Other Digital China is a highly recommended read.

\section{About the author}

$\mathrm{Yu}$-Wen Chen is Professor of Chinese Studies at the Department of Cultures at the University of Helsinki and Hosting Professor at the Department of Asian Studies at Palacky University in Czech Republic. 